\title{
A construção de materiais didáticos para o ensino de Geografia : o jogo da memória e os domínios morfoclimáticos
}

\author{
Gabriel Souza Cruz ${ }^{1}$ \\ Isabela Duarte Fernandes ${ }^{2}$ \\ Roberto Sete Azevedo Júnior ${ }^{3}$
}

\section{Resumo}

O presente artigo busca apresentar a atividade pedagógica realizada que teve como resultado a elaboração do jogo da memória acerca dos Domínios Morfoclimáticos do Brasil. Esta atividade foi aplicada aos alunos do sexto ano do ensino fundamental do Colégio Universitário Geraldo Reis, sob a orientação da professora Adriana Carvalho Silva e do professor Igor Robaina.

Palavras-Chave: Atividade pedagógica; Domínios Morfoclimáticos e Jogo da memória.

\section{Abstract}

This article aims to present the pedagogical activity performed by fellows of the workshop materials, which resulted in the development of memory play about morphoclimatic domains of Brazil. This activity was applied to students of the sixth year of elementary school of the University College Geraldo under the guidance of the teacher Adriana Carvalho Silva and of the teacher Igor Robaina.

Key words: Pedagogical activity; morphoclimatic domains and memory play.

\section{Desenvolvimento através do jogo}

A atividade pedagógica teve o objetivo de trabalhar com o conceito de paisagem, articulado a dimensão cartográfica, a fim de despertar o interesse dos alunos sobre o conteúdo abordado em sala de aula e contribuir para a construção do seu conhecimento de forma lúdica e prazerosa.

A atividade lúdica estimula a interação social que atua de forma positiva no desenvolvimento da zona proximal dos alunos, conforme aponta Vygotsky (apud OLIVEIRA, 1997: 64) e também desempenha uma importante função para o desenvolvimento cognitivo dos mesmos (OLIVEIRA, 1997). 
O jogo da memória como um recurso estratégico no ensino de Geografia foi utilizado a partir da temática dos Domínios Morfoclimáticos do Brasil. De acordo com os estudos de Aziz Ab'Saber (2003), e com a obrigatoriedade desta temática no ensino de Geografia, visto que Meio Ambiente é um dos temas transversais do currículo nacional (Secretaria Nacional de Educação, 1996) se buscou trabalhar com os diferentes aspectos da vegetação, do clima, do relevo, do solo, das condições hidrológicas e da própria biodiversidade de fauna, que configuram as paisagens naturais do território brasileiro.

Sob a concepção de Aziz Ab'Saber (2003), os grandes domínios paisagísticos brasileiros compreendem o domínio amazônico, o domínio do cerrado, o domínio dos mares de morros, o domínio da caatinga, o domínio das araucárias e o domínio das pradarias; como também as faixas de transição e o complexo do Pantanal.

Deste modo, consideramos os seis domínios que formam a realidade morfológica e paisagística brasileira para a confecção do jogo da memória. Assim, selecionamos as figuras referentes às paisagens, as faunas e floras endêmicas ${ }^{4}$ e suas devidas localizações cartográficas no território brasileiro.

\section{O jogo da memória}

Teoricamente, o trabalho se ancora em Vygostky (apud OLIVEIRA, 1997: 65) o qual trabalha com a ideia de que na situação escolar, a intervenção na zona de desenvolvimento proximal das crianças se configura de forma constante e deliberada. Desta forma, foi possível detectar que interação social com outras crianças, proposta pelo jogo da memória, foi fundamental para 0 desenvolvimento do aluno e possibilitando o seu aprendizado e conhecimento sobre conteúdo trabalhado em sala de aula.

A idéia de nível de desenvolvimento potencial - trata-se da capacidade do aluno de desempenhar tarefas com a ajuda de adultos ou companheiros mais capacitados -, desenvolvida por Vygotsky, foi articulada durante o jogo, pois a interferência dos próprios alunos, as colaborações do professor e dos bolsistas auxiliaram na construção do conhecimento dos alunos acerca do conteúdo abordado no jogo da memória e durante as aulas teóricas.

De acordo com Vygotsky, o professor interfere explicitamente sobre o aprendizado dos indivíduos no espaço escolar, especialmente na realização das atividades que ainda não estão consolidadas pelos alunos, ou seja, que os mesmos ainda não dominam completamente, conforme descreve Oliveira: 
"Como na escola o aprendizado é um resultado desejável, é o próprio objetivo do processo escolar, a intervenção é um processo pedagógico diferenciado. O professor tem o papel explícito de interferir na zona de desenvolvimento proximal dos alunos, provocando avanços que não ocorreriam espontaneamente". (OLIVEIRA, 1997: 62)

Deste modo, é importante apontar que a atividade lúdica facilita o aprendizado do educando, pois, muitas vezes, o conteúdo trabalhado em sala de aula de forma puramente verbal não é assimilado totalmente pelos alunos, principalmente os que pertencem ao primeiro e segundo ciclo do ensino fundamental.

A obra Para Ensinar e Aprender Geografia reflete a importância da construção de material didático para o ensino de geografia nas escolas, voltado para o ensino fundamental.

O seguinte trecho presente na obra referida acima destaca que:

"Os textos escritos, os materiais gráficos e cartográficos e outras linguagens, quando associados aos conceitos e conteúdos da disciplina focalizada, ampliam as oportunidades de compreensão do espaço geográfico e de entendimento do mundo". (PONTUSCHKA et al, 2003: 215)

Deste modo, articulamos o conteúdo dos domínios morfoclimáticos do Brasil, e o conceito de paisagem, que é um dos principais conceitos da ciência geográfica, utilizando como metodologia pedagógica a realização de uma atividade lúdica através do jogo da memória, a fim de possibilitar aos alunos a compreensão do estudo da paisagem, de maneira prazerosa e motivadora.

Neste sentido, o conceito que melhor se encaixa no caso do estudo dos domínios morfoclimáticos na perspectiva do ensino de Geografia é a paisagem, com a sua interface, caracterizando tanto a litosfera, hidrosfera e a atmosfera, desenvolvendo-se as formas vivas da Terra, onde se tem os processos para a formação dos domínios.

Essa visão de paisagem como interface vem do geólogo Eduard Suess, que no final do século XVIII publica a obra Das Antlitz der Erder, a face da Terra que procura explicar a superfície terrestre. Suess inclusive foi quem definiu primeiramente as noções de litosfera, hidrosfera e atmosfera. 
Surge após isso, a ideia de paisagem como interface entre homem e natureza. A ideia era simples: a superfície da Terra permite que a vida se aloje, feita de ambientes que são passiveis de intervenção humana. Com o surgimento da Ecologia a definição da paisagem como principal objeto do conteúdo à Geografia ganha destaque, pois vai de encontro com as tendências mais recentes de pesquisas da época.

É com Ratzel através de sua Antropogeografia ${ }^{5}$ que há a aproximação entre homens e os ambientes, e por volta de 1900, muitos geógrafos definem a disciplina de geografia como a ciência da paisagem ou das paisagens. Os geógrafos se interessavam apenas pelos fenômenos naturais, e vai surgindo um interesse pelas atividades dos homens e sua distribuição pela Terra. A obra de Ratzel ganha repercussão e os geógrafos passam a estudar a relação entre os homens e os ambientes em que vivem, a influência que o meio exerce sobre os indivíduos e por sua vez as transformações que os homens exercem sobre o meio ambiente.

A partir de então, a paisagem concebida como interface entre natureza e homem ganha destaque, conforme Paul Claval assinala no seguinte trecho: "Conceber a paisagem como uma interface transforma, de modo mais profundo do que se costuma dizer, as maneiras de analisá-la." (CLAVAL, In: CORRÊA; ROSENDAHL 2004: 22)

A atividade pedagógica se materializa com o jogo de memória simples em que as cartas estão dispostas com as imagens pra baixo e cada aluno vai virando uma carta de cada vez e tentando achar sua carta correspondente. Ao achá-la, o aluno ganha o direito de jogar mais uma vez. Caso não a encontre, o aluno passa a sua vez para o colega. São 40 cartas em que os alunos devem pegar as imagens correspondentes em relação às vegetações e animais endêmicos com suas determinadas legendas. Os alunos devem também fazer a relação dos domínios morfoclimáticos com sua devida localização na carta que continha o mapa do Brasil, com o determinado domínio destacado.

\section{Resultados}

Foi de grande valia e uma experiência interessante confeccionar e aplicar o jogo da memória para a turma de sexto ano. Assim que o jogo foi apresentado aos alunos, houve certa rejeição por parte de alguns e extrema receptividade por parte de outros alunos. Entendemos isso e já esperávamos pelo comportamento daqueles alunos que rejeitaram inicialmente a proposta 
pedagógica, por se tratar de um jogo que pode ser encarado como algo sem importância para alunos com idades em média entre doze e quatorze anos. Geralmente, os adolescentes nesta faixa etária não costumam dar muito valor a certas brincadeiras e jogos, concentrando seus interesses em busca de algo novo, de novas experimentações, mas mesmo assim insistimos que o jogo de memória com os domínios morfoclimáticos seria uma boa forma de passar 0 conteúdo.

Ficamos preocupados também porque inicialmente os alunos demoraram a fazer as associações entre o que estava nas cartas do jogo e o conteúdo ensinado em sala de aula, somente se preocupando em pegar as cartas relacionadas para fazer pontos. A assimilação e compreensão dos alunos perante o jogo, na perspectiva de que não servia somente como uma brincadeira em si, mas também como uma forma de aprendizagem demorou, mas entendemos que isso fazia parte da proposta e que o conteúdo não seria defasado em relação a este fato.

De maneira geral, o resultado foi satisfatório. A maioria dos alunos se inseriu na brincadeira desde o início, com empolgação, até com certa euforia, querendo pontuar de qualquer maneira, tentando ate certas "trapaças". Depois, os alunos que ficaram desconfiados e que, a princípio, não queriam interagir, acabaram participando, pois viram que todos estavam ali jogando e se divertindo, então, eles não queriam mais ficar de fora. A aplicação deste jogo congregou uma maior interação dos alunos com os professores, e tornou conteúdo mais prazeroso e fácil de ser explicado.

Do ponto de vista dos resultados cognitivos em relação à formação de conhecimento dos domínios morfoclimáticos do Brasil, obtivemos também um resultado satisfatório. Como dito anteriormente, os alunos demoraram um pouco para fazer a relação entre o que estava nas cartas e o conteúdo aplicado em sala de aula sendo preciso a intervenção dos bolsistas e do professor para que atentassem para tal relação, mas nada que comprometesse a obtenção de conhecimento.

Podemos detectar até alguns casos em que uma imagem de uma Mata Atlântica muito densa foi confundida com a Floresta Amazônica e enxergamos nisso um avanço no entendimento da matéria, pois aquela imagem poderia ser mesmo de uma floresta equatorial, por ter a vegetação densa, muito semelhante à Floresta Amazônica.

Como guisa de conclusão, a atividade proporcionou aos alunos uma experiência nova e prazerosa no ensino de Geografia, especificamente nos conteúdos relacionados aos domínios morfoclimáticos, evidenciando resultados 
satisfatórios e o objetivo de ensinar de maneira lúdica e comprometida geograficamente.

\section{Notas}

1- Graduando do $8^{\circ}$ período do curso Geografia da Univ ersidade Federal Fluminense.

2- Graduanda do $7^{\circ}$ período do curso Geografia da Univ ersidade Federal Fluminense.

3- Graduando do 8ํㅜ período do curso Geografia da Universidade Federal Fluminense.

4- Segundo o dicionário Aurélio, o termo endêmico significa aquilo que é próprio de uma região

5- Antropogeografia é a obra de Ratzel publicada em 1882 e que inicia a Geografia Humana na concepção de alguns teóricos.

\section{Referências bibliográficas}

AB'SABER, Aziz Nacib. Os domínios de natureza no Brasil: potencialidades paisagísticas. São Paulo: Ateliê editorial, 2003.

BRASIL. Secretaria de Educação Fundamental. Parâmetros Curriculares Nacionais: Geografia. Brasília: MEC/ SEF, 1998.

CLAVAL, Paul. A paisagem dos geógrafos. In: CORRÊA, Roberto Lobato \& ROSENDAHL, Zeny. (orgs.). Paisagens, textos e identidade. Rio de Janeiro EdUerj, 2004.

OLIVEIRA, Marta Kohl. Vygotsky: Aprendizado e Desenvolvimento - Um processo sócio-histórico. São Paulo: Scipione, 1997.

PONTUSCHKA, Nídia Nacib; PAGANELLI Tomoko lyda; CACETE Núria Hanglei. Para Ensinar e Aprender Geografia. 1a ed. Sao Paulo: cortez, 2007. 